This is the peer reviewed version of the following article: DOI: 10.1002/elan.201500205, which been published in final form at http://onlinelibrary.wiley.com/doi/10.1002/elan.201500205/abstract.

http://www.interscience.wiley.com/

\title{
The use of graphitic carbon nitride based composite anodes for lithium-ion battery applications
}

\author{
Thomas S. Miller $^{a^{*}}$, Ana Belen Jorge ${ }^{b}$, Andrea Sella ${ }^{a}$, Furio Corà $^{a}$, Paul R. Shearing ${ }^{b}$, Daniel J.L. Brett ${ }^{b}$, \\ Paul F. McMillan ${ }^{a^{*}}$ \\ a Department of Chemistry, University College London, 20 Gordon Street, London, WC1H 0AJ, UK \\ b Electrochemical Innovation Lab, Department of Chemical Engineering, University College London, \\ Torrington Place, London WC1E 7JE, UK \\ * p.f.mcmillan@ucl.ac.uk, t.miller@ucl.ac.uk.
}

\begin{abstract}
Graphitic carbon nitride $(\mathrm{gCN})$ is shown to undergo lithium insertion reactions applicable with lithium-ion battery anodes. Lithium capacity was found to be substantially lower than theoretically expected, so the properties of gCN composited with conducting graphite (CG), which was added to improve the performance, were investigated. The electrodes exhibited a systematic increase in lithium uptake with CG content, but the capacity never exceeded that of graphite. It is shown that electron transport via conducting pathways was limiting. $\mathrm{Li}^{+}$uptake for $10 \% \mathrm{gCN}$ was similar to a graphite electrode, indicating that gCN does play a role in determining the storage capacity.
\end{abstract}

Keywords: Carbon Nitride, Lithium-ion battery, Anode, Resistivity, Composite.

\section{Introduction}

Anodes based on graphitic carbon are routinely used in lithium-ion batteries (LIBs) due to their ability to intercalate lithium, ultimately forming the stoichiometric compound $\mathrm{LiC}_{6}$ [1]. Unfortunately their reversible $\mathrm{Li}$-storage capacity in practical applications is often noticeably lower than the theorical value [2]. Nitrogen doped carbon materials have demonstrated significantly higher capacities than graphite [3, 4] and do not suffer from issues that hinder development of other high capacity anode materials, e.g. extreme (up to $300 \%$ ) volume changes with $\mathrm{Li}-\mathrm{Si}$ anode systems $[5,6]$. This development has sparked an interest in a range of $\mathrm{C}, \mathrm{N}$ containing compounds for use in LIBs [7-9], including graphitic carbon nitride ( $\mathrm{gCN}$ ) materials [10-12].

Different families of gCN compounds exist with structures based on $s$-triazine or heptazine (tri-striazine) units linked by $-\mathrm{N}=$ or $-\mathrm{NH}$ - (imide) groups $[13,14]$. Polymeric structures like Liebig's melon $\left(\left[\mathrm{C}_{6} \mathrm{~N}_{7}\left(\mathrm{NH}_{2}\right)(\mathrm{NH})\right]_{\mathrm{n}}\right)$ [15] or melem $\left(\mathrm{C}_{6} \mathrm{~N}_{7}\left(\mathrm{NH}_{2}\right)_{3}\right)$ [16] are produced by thermal treatment of precursors such as dicyandiamide (DCDA: $\mathrm{C}_{2} \mathrm{~N}_{4} \mathrm{H}_{4}$ ) and consist of ribbons of heptazine chains linked by -NH- and $\mathrm{NH}_{2}$ - groups [17-19]. Synthesis at higher temperature or prolonged annealing in $\mathrm{N}_{2}$ atmospheres results in further layer condensation as the ribbon-like units become linked with loss of $\mathrm{NH}_{3}$ components [20]. Using melamine $\left(\mathrm{C}_{3} \mathrm{~N}_{6} \mathrm{H}_{9}\right)$ as a precursor also leads to materials with triazine based structures, which can be extended to form infinite graphene-like sheets with composition $\mathrm{C}_{3} \mathrm{~N}_{4}$ [21].

Density functional theory (DFT) calculations have shown that idealized models of gCN structures have a potential Li capacity of $534 \mathrm{~mA} \mathrm{~h} \mathrm{~g}^{-1}$ [11], arising from the Li ions residing in intra-layer voids or 
intercalated between the gCN layers. Experimental work has indeed shown the ability of $\mathrm{gCN}$ varieties to store lithium [12], but the capacities achieved were over an order of magnitude lower than those predicted $[10,12]$. The $\mathrm{Li}^{+}$uptake capacity of $\mathrm{gCN}$ materials prepared from 1:1 mixtures of DCDA and melamine treated at temperatures between $550-650^{\circ} \mathrm{C}$ has been investigated previously [12]. The least condensed materials prepared at lower temperatures formed highly porous solids that were found to exhibit the highest uptake capacity. In the present study we used this same material, prepared at $550^{\circ} \mathrm{C}$. gCNs are semiconductors with band gaps in the region of $2.7 \mathrm{eV}$ [22], a property which has been utilised in various photocatalytic reactions [22-25]. Intrinsic semiconductivity is clearly not an ideal property for a LIB anode material where current must flow freely [26], but some semiconducting materials are effective anode materials when they are within conductive matrices [27].

In this work we investigate the $\mathrm{Li}$ storage capacity of mechanically formed composites of $\mathrm{gCN}$ and conductive graphite (CG) as potential LIB anode materials. CG is added to the $\mathrm{gCN}$ in varying ratios to optimise the electrical conductivity of the anode, with the aim of unlocking the potentially high Li storage capacity of the $\mathrm{gCN}$.

\section{Material and methods}

\subsection{Synthesis and characterisation of $\mathrm{gCN}$}

Melamine (1.5 g, 99\%, Sigma-Aldrich) and dicyandiamide (1.5 g, 99\%, Sigma-Aldrich) were ground together then packed into an alumina boat. The boat was then heated under flowing $\mathrm{N}_{2}$ at $10{ }^{\circ} \mathrm{C} \mathrm{min}{ }^{-1}$ to $550{ }^{\circ} \mathrm{C}$ in a tube furnace (Carbolite, MTF 12/38/250) and held for $18 \mathrm{~h}$, before being cooled to room temperature. Micro-Raman spectra were taken using a Renishaw InVia spectrometer fitted with a $325 \mathrm{~nm}$ UV laser. X-ray diffraction (XRD) patterns were taken using a STOE STADI P diffractometer using Ka radiation. Field emission scanning electron microscope (FE-SEM) images were taken using a JEOL JSM$6700 \mathrm{~F}$ system. Transmission electron microscope (TEM) images were taken using a JEOL JEM-2100 TEM using an accelerating voltage of $200 \mathrm{kV}$.

Characterisation of the as synthesised $\mathrm{gCN}$ can be seen in Fig 1 and similar results are also reported elsewhere $[12,22]$.
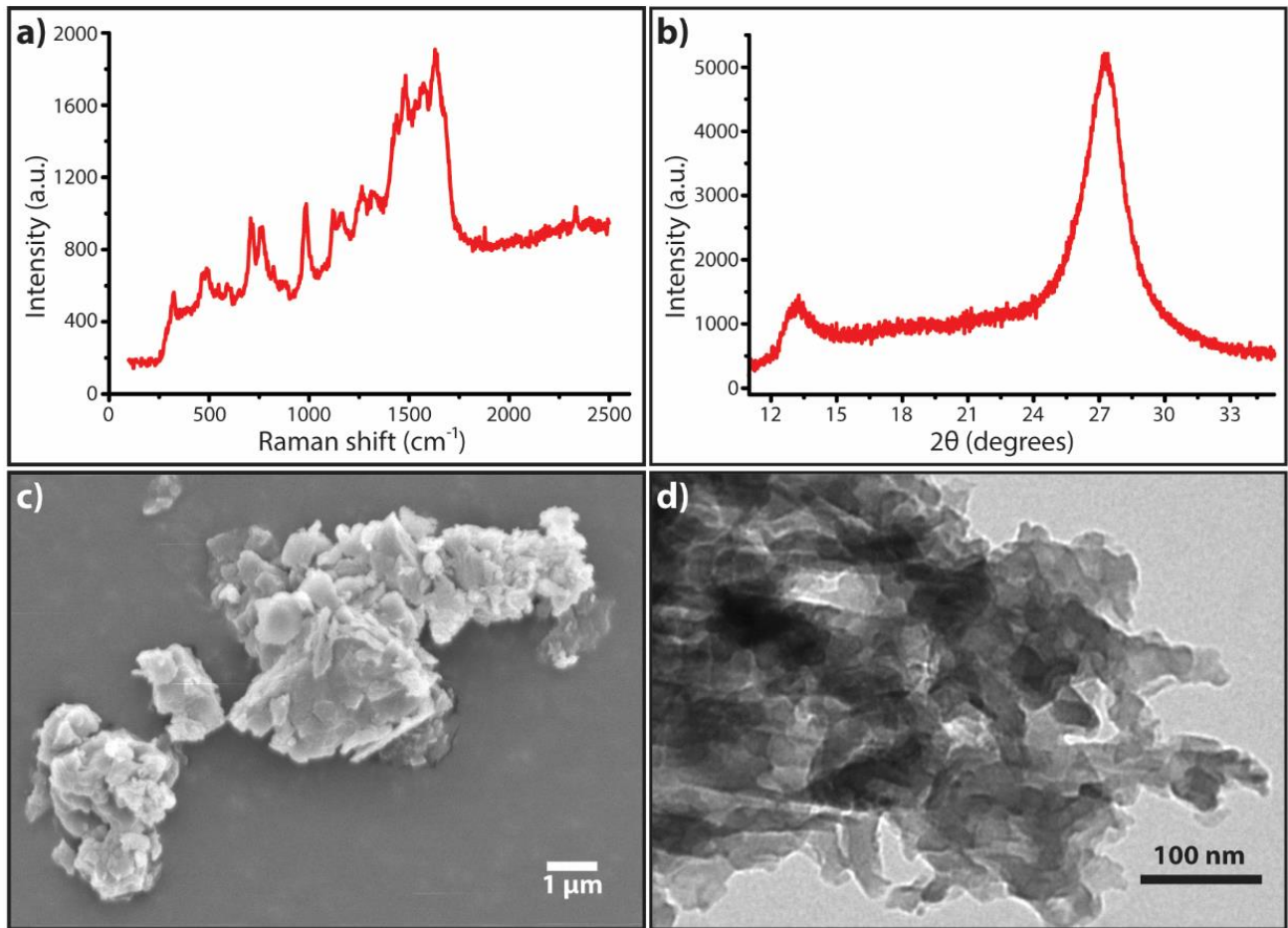

Fig. 1 a) Micro-Raman spectrum of gCN taken using a $325 \mathrm{~nm}$ exitation. b) Powder x-ray diffraction pattern of gCN. c) FE-SEM image of as synthesised gCN d) TEM image of as synthesised gCN. 


\subsection{Electrode preparation and cell construction}

To prepare electrodes, polyvinylidenefluoride (PVDF, 10 wt. \%) was mixed with the gCN and CG (MTI Corporation) in different ratios between 1:0 and 0:1 (by dry weight) and ground by hand to form a homogeneous paste in 1-methyl-2-pyrrolidinone (NMP, anhydrous $99.5 \%$, Sigma-Aldrich). These slurries were then applied to $\mathrm{Cu}$ foils at a constant thickness then dried at $80^{\circ} \mathrm{C}$ for $12 \mathrm{~h}$ before being punched into $1 \mathrm{~cm}^{2}$ disks.

Coin cell construction (CR2032 geometry) was performed inside a glove box (MBraun, Ar atmosphere, $<1 \mathrm{ppm} \mathrm{O}_{2}, \mathrm{H}_{2} \mathrm{O}$ ). The gCN/CG composite electrode was separated from the $1 \mathrm{~cm}^{2} \mathrm{Li}$ disk cathode by an electrolyte-soaked microporous polyethylene film. The electrolyte (BASF, used as purchased) consisted of $1 \mathrm{M} \mathrm{LiPF}_{6}$ and a 1:1:1 mixture of ethylene carbonate (EC), dimethyl carbonate (DMC) and ethyl methyl carbonate (EMC).

\subsection{Electrical and electrochemical testing}

Electrochemical tests were performed using a Maccor battery test system (Series 4300). Cyclic voltammograms $(\mathrm{CV})$ were performed at $0.5 \mathrm{mV} \mathrm{s}^{-1}$ between $2.0 \mathrm{~V}$ and $0.05 \mathrm{~V}$ and cells were cycled galvanostatically between $0.05 \mathrm{~V}$ and $3.5 \mathrm{~V}$ at a constant current Charge-Discharge (C-D) rate of $0.02 \mathrm{Ag}$ 1 .

Resistivity measurements were performed using square $1 \times 1 \mathrm{~cm}$ electrodes via the Van der Pauw method [28] which measures the specific resistivity of flat samples of arbitrary shape with small electrical contacts. These measurements were made with a Hall effect measurement system (Ecopia HMS-3000). Electrode slurries for these tests were prepared as above, but on top of a non-conductive Kapton film (DuPont). For resistivity measurements electrical connections were made via triangular Au contacts ( 1.5 $\mathrm{mm}^{2}$ ) sputtered at the four electrode corners; to ensure these contacts were ohmic $\mathrm{I} / \mathrm{V}$ and $\mathrm{I} / \mathrm{R}$ measurements were performed before the specific resistivity was measured.

This measurement required the thickness of the electrodes to be known, so equivalent electrodes were cut and their thickness measured using the FE-SEM with the electrode edge perpendicular to the beam direction. The values used were the mean of at least three measurements from three separate electrodes.

In a typical resistivity measurement, a DC current of $1 \mathrm{~mA}$ was automatically applied between contacts 1 and $2\left(\mathrm{I}_{1 / 2}\right)$ and, assuming the contacts were numbered from 1 to 4 anti-clockwise, $\mathrm{V}$ was automatically measured between contact 4 and $3\left(V_{4 / 3}\right)$. This was then repeated with $I_{2 / 3}$ and $V_{1 / 4}$ and the further two arrangements $\left(\mathrm{I}_{3 / 4}, \mathrm{~V}_{2 / 1}\right.$ and $\left.\mathrm{I}_{4 / 1}, \mathrm{~V}_{3 / 2}\right)$. From this the software was able to calculate resistivity with the $\mathrm{Van}$ der Pauw equation.

\section{Results and Discussion}

Before investigating the use of $\mathrm{gCN}$ as a LIB anode material, it was first essential to thoroughly characterise the $\mathrm{gCN}$ itself. Fig. 1 a) shows the micro-Raman spectrum of $\mathrm{gCN}$ in which many peaks can be observed, this was taken using a UV $(325 \mathrm{~nm})$ excitation to avoid intense fluorescence. The key characteristic features for $\mathrm{gCN}$ identification are $\mathrm{C}-\mathrm{N}$ stretching vibrations in the region of $1200-1700$ $\mathrm{cm}^{-1}$ and peaks observed near 690 and $980 \mathrm{~cm}^{-1}$. The peak near $690 \mathrm{~cm}^{-1}$ is assigned to a doubly degenerate mode associated with in-plane bending vibrations of the $\mathrm{C}-\mathrm{N}-\mathrm{C}$ linked heptazine linkages. The $980 \mathrm{~cm}^{-1}$ peak is assigned to a symmetric heptazine $\mathrm{N}$-breathing mode [22].

Fig. 1 b) shows a powder XRD pattern for the gCN, with two broad peaks occurring at around 12.5 and $27.5^{\circ} 2 \theta$, which correlate with an in-plane repeat distance of a single tri-s-triazine unit and the 002 reflection of graphitic layered materials respectively [22]. The breadth of these peaks shows that the $\mathrm{gCN}$ is not a highly crystalline material. 
Fig. $1 \mathrm{c}$ ) and d) show representative FE-SEM and TEM images of the as synthesised gCN respectively. From both it is apparent that the $\mathrm{gCN}$ is not highly crystalline and ordered like graphite, but instead if forms an open textured material with, as indicated by XRD, structure on a much more localised level. The combination of all these characterisation data confirm that the material in question is indeed $\mathrm{gCN}$.

To investigate lithium storage capacity as a function of the $\mathrm{gCN}$ content of electrodes, a range of electrodes was produced containing between $90 \% \mathrm{gCN}(0 \% \mathrm{CG}, 10 \% \mathrm{PVDF})$ and $0 \% \mathrm{gCN}(90 \% \mathrm{CG}$, $10 \%$ PVDF). The FE-SEM images in Fig. 2 are representative of the electrodes produced. The image in Fig. 2 a) is of an electrode which only consisted of $\mathrm{gCN}$ and binder and it clearly shows a porous aggregated texture, which has also been observed previously $[12,22]$. When this electrode is compared to the one shown in Fig. 2 b), containing $65 \% \mathrm{gCN}$ and $25 \% \mathrm{CG}$, one can identify platelet type structures of the CG dispersed throughout the material and contacting the gCN. From the inset images in Fig. 2 a) and b) it is apparent that both slurries have made a good physical contact to the $\mathrm{Cu}$ support (bottom left of image).
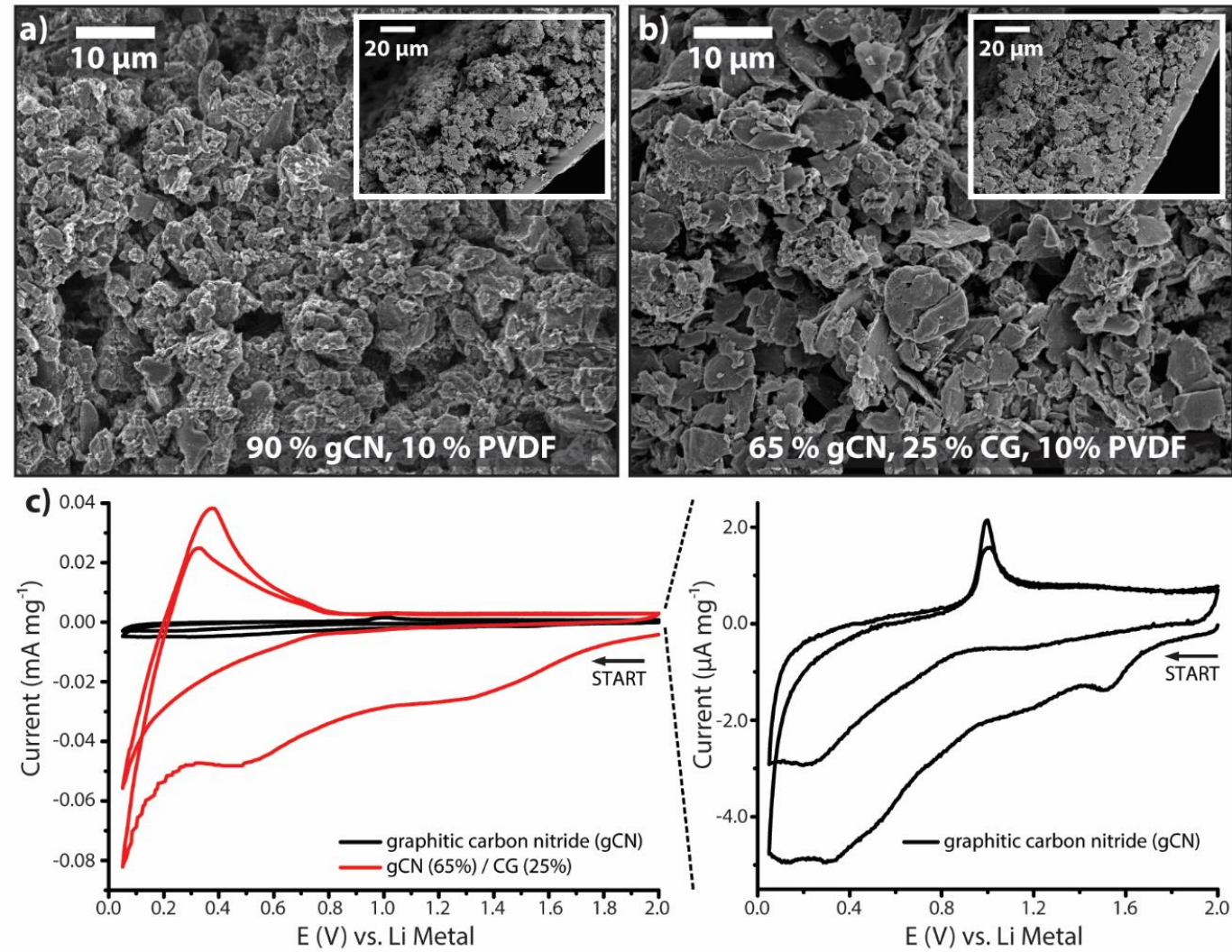

Fig. 2 a) FE-SEM images of gCN (90\%) and PVDF (10\%) electrode, top view (main image) and side view (inset). b) FE-SEM images of gCN (65 \%), CG (25\%) and PVDF (10\%) electrode, top view (main image) and side view (inset). c) CVs of $90 \%$ (black line) and $65 \%$ (red line) gCN electrodes at $0.5 \mathrm{mV} \mathrm{s}-1 \mathrm{vs.} \mathrm{Li} \mathrm{metal} \mathrm{in} \mathrm{a} \mathrm{coin} \mathrm{cell,} \mathrm{both}$ the first and second potential cycles are shown. $\mathrm{CV}$ on right is a magnification of the $90 \% \mathrm{gCN}$ voltammogram.

CVs of the $90 \%$ and $65 \%$ gCN electrodes can be seen in Fig. 2 c) with the left hand side showing the two voltammograms overlaid and the right hand side showing a magnification of the $90 \% \mathrm{gCN}$ electrode response. Both Fig. $2 \mathrm{CVs}$ have a broad reduction peak at ca. $1.5-0.9 \mathrm{~V}$ vs. Li, which can be attributed to the reduction of surface groups and is commonly seen for carbon based electrodes [29, 30]. Also, the first cycle of both CVs feature a broad reduction peak with increased magnitude in the region of $0.9-0.2 \mathrm{~V}$, which is most likely to be associated with formation of a solid-electrolyte interface (SEI) layer [31], although the nature of this layer in $\mathrm{gCN}$ electrodes is not yet understood. It is, however, clearly apparent that the response from the two materials differs significantly in magnitude, with the de- lithiation peak for 
the $65 \%$ gCN electrode (ca. $0.4 \mathrm{~V}$ vs. Li) reaching twenty times the current density of the $90 \% \mathrm{gCN}$ electrode (ca. $1.0 \mathrm{~V}$ vs. Li), indicating significantly greater lithium capacity. It is also notable that this peak appears at much higher overpotentials for the $90 \% \mathrm{gCN}$ anode, indicating a more kinetically hindered process [32].
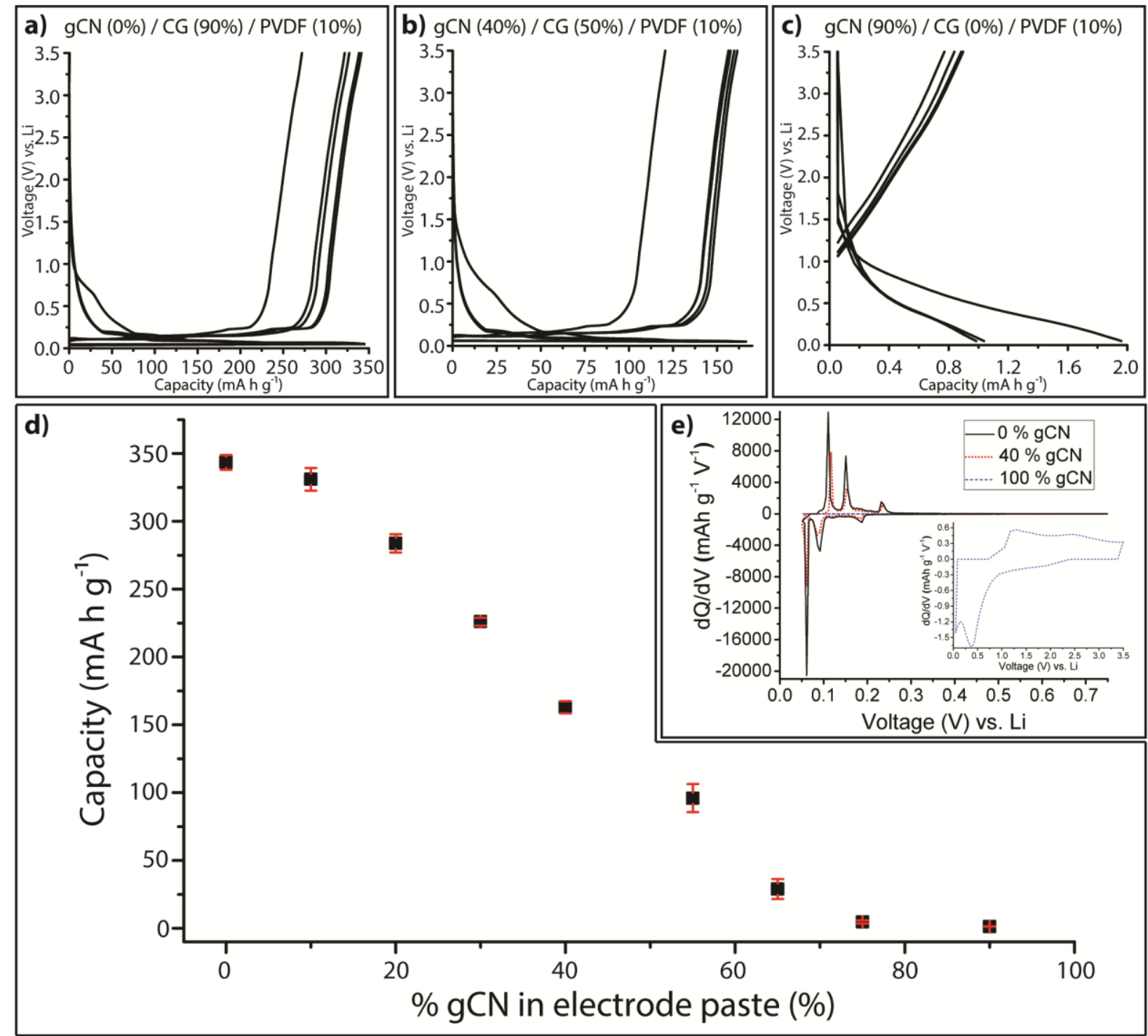

Fig. 3 a) Charge/discharge profile for gCN (0\%) / CG (90\%) / PVDF (10\%) anode at $0.02 \mathrm{~A} \mathrm{~g}^{-1}$. b) Charge/discharge profile for $\mathrm{gCN}(40 \%) / \mathrm{CG}(50 \%) / \mathrm{PVDF}(10 \%)$ anode at $0.02 \mathrm{~A} \mathrm{~g}^{-1}$. c) Charge/discharge profile for $\mathrm{gCN}(90 \%) / \mathrm{CG}$ $(0 \%) /$ PVDF $(10 \%)$ anode at $\left.0.02 \mathrm{~A} \mathrm{~g}^{-1} . \mathrm{d}\right)$ Plot of mean $5^{\text {th }}$ cycle capacity vs. percentage gCN in the electrode material, between $90 \% \mathrm{gCN}(10 \% \mathrm{PVDF})$ and $0 \% \mathrm{gCN}(90 \% \mathrm{CG}, 10 \% \mathrm{PVDF})$. Points are the mean value from multiple cells with error bars showing one standard deviation. e) Plot of $5^{\text {th }}$ cycle differential capacity vs cell voltage (vs. Li) for $0 \%, 40 \%$ and $100 \%$ gCN cells.

To further analyse the performance of the $\mathrm{gCN}$ composite anodes, C-D measurements were performed of the full range of compositions from $0 \% \mathrm{gCN}$ to $90 \% \mathrm{gCN}$, at $0.02 \mathrm{~A} \mathrm{~g}^{-1}$, between $3.5 \mathrm{~V}$ and $0.05 \mathrm{~V}$ (Fig. 3). In Fig. 3 a) the C-D plot for an electrode consisting of just CG and binder can be seen and shows the common irreversible capacity loss between $\sim 0.8 \mathrm{~V}$ and $\sim 0.3 \mathrm{~V}$ on the first cycle, due to the formation of an amorphous SEI layer [31]. However, after the first cycle the electrode settled, resulting in a stable capacity of $\sim 350 \mathrm{~mA} \mathrm{~h} \mathrm{~g}^{-1}$ which is in the usual range for CG anodes $[2,31]$ and shows that the processes used to 
produce the electrodes were effective. When an electrode containing $40 \% \mathrm{gCN}$ underwent $\mathrm{C}-\mathrm{D}$, the resultant plot, shown in Fig. 3 b), is similar to that for the $90 \%$ CG anode, but with a measurably lower maximum capacity of $\sim 175 \mathrm{~mA} \mathrm{~h} \mathrm{~g}^{-1}$. This represents a ca. $50 \%$ capacity loss through the addition of 40 $\% \mathrm{gCN}$, indicating that the $\mathrm{gCN}$ contributes little to the capacity and may even reduce the capacity of the CG, possibly through disruption of conduction pathways. The C-D plot of an anode consisting of only $\mathrm{gCN}$ and binder (Fig. $3 \mathrm{c}$ ) is quite different to the others shown. On the first cycle the capacity only reached $2 \mathrm{~mA} \mathrm{~h} \mathrm{~g}^{-1}$, which stabilised at $1 \mathrm{~mA} \mathrm{~h} \mathrm{~g}^{-1}$ on subsequent cycles, a capacity dramatically lower than both the example for the pure $\mathrm{CG}$ anodes and that predicted for $\mathrm{gCN}$ [11].

The chart in Fig. 3 d) shows the $5^{\text {th }}$ cycle capacity (used to ensure cell stabilisation) plotted vs. the percentage of $\mathrm{gCN}$ in the anode composite. In this graph we observe a clear inverse correlation between the amount of $\mathrm{gCN}$ and the capacity, which effectively reaches a minimum value at $\sim 75 \% \mathrm{gCN}$. This is likely the point at which the CG forms isolated 'islands' of local conductivity rather than an interconnected conducting network. It is noticeable, nonetheless, that the capacity for $10 \% \mathrm{gCN}$ is almost as high as that for $0 \% \mathrm{gCN}$ ( 331 vs. $342 \mathrm{~mA} \mathrm{~h} \mathrm{~g}^{-1}$ ), possibly indicating that at low concentrations the gCN is capable of significantly contributing to capacity. The overall trend does, however, demonstrate that the $\mathrm{gCN}$ is not contributing greatly to the lithium capacity, the vast majority of which is coming from the CG.

In $5^{\text {th }}$ cycle differential capacity $(\mathrm{dQ} / \mathrm{dV})$ plots of cells where $\mathrm{gCN}$ is mixed with $\mathrm{CG}$, three reversible cathodic peaks can be seen below $0.3 \mathrm{~V}$ (vs. Li) during Li intercalation and deintercalation cycles (Fig. 3 e), this is usual for graphite anodes [33]. The cell containing $40 \% \mathrm{gCN}$ shows lower a capacity and a slightly higher overpotential for these processes. The inset in Fig 3 e) shows the same plot for the $100 \%$ gCN anode which, as demonstrated in other components of Fig. 3, shows dramatically lower capacity and a lack of intercalation processes until $>1 \mathrm{~V}$.

The successful insertion of $\sim 3 \mathrm{wt} \% \mathrm{Li}$ into $\mathrm{gCN}$ has previously been reported via liquid-ammonia assisted chemical intercalation [34], suggesting that $\mathrm{gCN}$ is able to accommodate large quantities of Li. This indicates that in our case the limited Li uptake may be due to the low electrical conductivity of the individual gCN particles. To investigate if electrical conductivity was indeed the limiting factor, resistivity measurements were performed using the Van der Pauw method (see section 2.3) on composite anode materials prepared on insulating Kapton films (Fig. 4).

Fig. 4 shows that resistivity increased dramatically as the amount of $\mathrm{gCN}$ in the composite is increased, in an almost exponential fashion. When the amount of $\mathrm{gCN}$ in the composite exceeded $65 \%$ the resistivity exceeded the range measurable with the set-up. At $75 \% \mathrm{gCN}$ the lithium capacity was near its minima (Fig. 3 d) and resistivity was significantly increased, suggesting that electrical resistivity was indeed the factor which limited the performance of the $\mathrm{gCN}$ anodes.

\section{Conclusions}

In this work we have shown that although it has been predicted that anodes based on gCNs should have a higher lithium capacity than the traditional graphite, the practical capacity of these materials is much lower, with values for pure $\mathrm{gCN}$ anodes as low as $1 \mathrm{~mA} \mathrm{~h} \mathrm{~g}^{-1}$. Although there is an indication that a low ( $10 \mathrm{wt} \%$ ) concentration of gCN increased capacity above that expected for an anode with $10 \%$ inert material, the majority of the capacity for these composite electrodes was shown to be provided by the graphite. By measuring the resistivity of the composite anodes we have demonstrated a clear correlation between capacity and resistivity, indicating that the electrical conductivity of these gCNs severely limits their $\mathrm{Li}^{+}$uptake. 


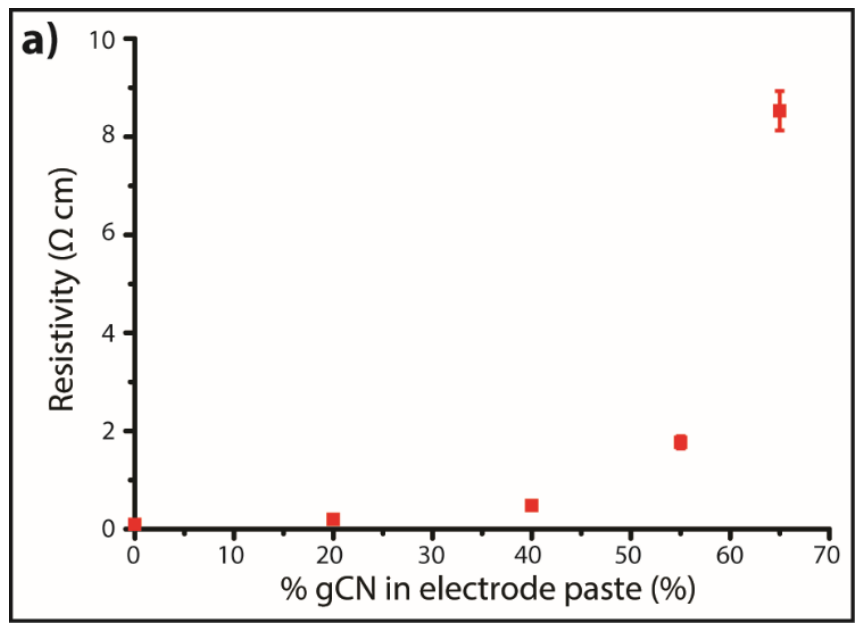

Fig. 4 a) Plot of resistivity vs. percentage gCN in the electrode material, between $65 \%$ gCN (25\% CG, $10 \%$ PVDF) and $0 \% \mathrm{gCN}(90 \% \mathrm{CG}, 10 \% \mathrm{PVDF})$. Points are the mean value over 3 individual electrodes, with error bars showing one standard deviation.

\section{Acknowledgements}

The authors would like to acknowledge support from the EPSRC (EP/K503745/1 and EP/L017091/1).

\section{References}

[1] Ohzuku, T., Iwakoshi, Y., Sawai, K., J. Electrochem. Soc. 1993, 140, 2490-2498.

[2] Li, H., Wang, Z., Chen, L., Huang, X., Adv. Mater. 2009, 21, 4593-4607.

[3] Wang, H., Zhang, C., Liu, Z., Wang, L., Han, P., Xu, H., Zhang, K., Dong, S., Yao, J., Cui, G., J. Mater. Chem. 2011, 21, 5430-5434.

[4] Wu, Z.-S., Ren, W., Xu, L., Li, F., Cheng, H.-M., ACS Nano 2011, 5, 5463-5471.

[5] Boukamp, B. A., Lesh, G. C., Huggins, R. A., J. Electrochem. Soc. 1981, 128, 725-729.

[6] Kasavajjula, U., Wang, C., Appleby, A. J., J. Power Sources 2007, 163, 1003-1039.

[7] Zhong, D. Y., Zhang, G. Y., Liu, S., Wang, E. G., Wang, Q., Li, H., Huang, X. J., Appl. Phys. Lett. 2001, 79, 3500-3502.

[8] Qie, L., Chen, W.-M., Wang, Z.-H., Shao, Q.-G., Li, X., Yuan, L.-X., Hu, X.-L., Zhang, W.-X., Huang, Y.-H., Adv. Mater. 2012, 24, 2047-2050.

[9] Bulusheva, L. G., Okotrub, A. V., Kurenya, A. G., Zhang, H., Zhang, H., Chen, X., Song, H., Carbon, 2011, 49, 4013-4023.

[10] Veith, G. M., Baggetto, L., Adamczyk, L. A., Guo, B., Brown, S. S., Sun, X.-G., Albert, A. A., Humble, J. R., Barnes, C. E., Bojdys, M. J., Dai, S., Dudney, N. J., Chem. Mater. 2013, 25, 503-508.

[11] Wu, M., Wang, Q., Sun, Q., Jena, P., J. Phys. Chem. C 2013, 117, 6055-6059.

[12] Jorge, A. B., Corà, F., Sella, A., McMillan, P. F., Brett, D. J. L., International Journal of Nanotechnology 2014, $11,737-746$.

[13] Goglio, G., Foy, D., Demazeau, G., Mater. Sci. Eng. R. 2008, 58, 195-227.

[14] Pauling, L., Sturdivant, J. H., Proc. Natl. Acad. Sci. U.S.A. 1937, 23, 615-620. 
[15] Liebig, J., Annalen der Physik 1835, 110, 570-613.

[16] Sattler, A., Schnick, W., Z. Anorg. Allg. Chem. 2006, 632, 238-242.

[17] Kroke, E., Schwarz, M., Coord. Chem. Rev. 2004, 248, 493-532.

[18] Lotsch, B. V., Döblinger, M., Sehnert, J., Seyfarth, L., Senker, J., Oeckler, O., Schnick, W., Chem. Eur. J. 2007, $13,4969-4980$.

[19] Schwarzer, A., Saplinova, T., Kroke, E., Coord. Chem. Rev. 2013, 257, 2032-2062.

[20] Komatsu, T., J. Mater. Chem. 2001, 11, 802-803.

[21] Algara-Siller, G., Severin, N., Chong, S. Y., Björkman, T., Palgrave, R. G., Laybourn, A., Antonietti, M., Khimyak, Y. Z., Krasheninnikov, A. V., Rabe, J. P., Kaiser, U., Cooper, A. I., Thomas, A., Bojdys, M. J., Angew. Chem. Int. Ed. 2014, 53, 7450-7455.

[22] Jorge, A. B., Martin, D. J., Dhanoa, M. T. S., Rahman, A. S., Makwana, N., Tang, J., Sella, A., Corà, F., Firth, S., Darr, J. A., McMillan, P. F., J. Phys. Chem. C 2013, 117, 7178-7185.

[23] Su, F., Mathew, S. C., Lipner, G., Fu, X., Antonietti, M., Blechert, S., Wang, X., J. Am. Chem. Soc. 2010, 132, 16299-16301.

[24] Wang, Y., Wang, X., Antonietti, M., Angew. Chem. Int. Ed. 2012, 51, 68-89.

[25] Wang, X., Maeda, K., Thomas, A., Takanabe, K., Xin, G., Carlsson, J. M., Domen, K., Antonietti, M., Nat Mater 2009, 8, 76-80.

[26] Kiehne, H. A., Battery Technology Handbook, Taylor \& Francis 2003.

[27] Chan, C. K., Peng, H., Liu, G., McIlwrath, K., Zhang, X. F., Huggins, R. A., Cui, Y., Nat Nano 2008, 3, 31-35.

[28] Van der Pauw, L. J., Philips Res. Rep. 1958, 13, 1-9

[29] Matsumura, Y., Wang, S., Mondori, J., J. Electrochem. Soc. 1995, 142, 2914-2918.

[30] Wang, Z.-L., Xu, D., Wang, H.-G., Wu, Z., Zhang, X.-B., ACS Nano 2013, 7, 2422-2430.

[31] Goodenough, J. B., Kim, Y., Chem. Mater. 2009, 22, 587-603.

[32] Bard, A. J., Faulkner, L. R., Electrochemical Methods: Fundamentals and Applications, Wiley 1980.

[33] Dahn, J. R., Phys. Rev. B 1991, 44, 9170-9177.

[34] Yin, Y., Han, J., Zhang, X., Zhang, Y., Zhou, J., Muir, D., Sutarto, R., Zhang, Z., Liu, S., Song, B., RSC Advances 2014, 4, 32690-32697. 